\title{
The Application of the Modular Multilevel Matrix Converter in High- Power Wind Turbines
}

\author{
Matías Díaz ${ }^{1}$, Mauricio Espinoza ${ }^{2}$, Andrés Mora $^{3}$, Roberto Cárdenas ${ }^{4}$, Pat Wheeler ${ }^{5}$ \\ ${ }^{1}$ Electrical Engineering Department, University of Santiago of Chile, Chile \\ ${ }^{2}$ School of Electrical Engineering, University of Costa Rica, Costa Rica \\ ${ }^{3}$ Electrical Engineering Department, Universidad Técnica Federico Santa María, Chile \\ ${ }^{4}$ Electrical Engineering Department, University of Chile, Chile \\ ${ }^{5}$ PEMC Group, Faculty of Engineering, The University of Nottingham, UK
}

\section{Acknowledgments}

The support of Fondecyt grant Nr. 1140337, the Basal Project AC3E FB0008 and the P.hD. Scholarship CONICYT / Doctorado Nacional / 2013-21130721 are kindly acknowledged.

\section{Keywords}

«Wind Turbines», « Fault Ride-Through »,« Multilevel Converters », « Matrix Converter».

\begin{abstract}
The trend in wind turbines has shown an ongoing power rating growth, reaching sizes up to $10 \mathrm{MW}$. Multilevel converters have therefore become a favourable solution for Multi-MW Wind Energy Conversion Systems (WECSs), due to high efficiency, reliability, controllability and the ability to reach high power/voltage ratings. Moreover, stringent grid codes to regulate the connection of WECSs to the electrical networks have been developed in countries with a high penetration of wind energy. In this context, this paper introduces the novel application of the Modular Multilevel Matrix Converter for interfacing Multi-MW Wind Turbines to provide decoupled input-output regulation, variable speed operation and fulfilment of modern grid codes.
\end{abstract}

\section{Introduction}

Wind Energy is the industry with greatest and fastest growth among all the renewable electrical energy sources. The wind energy production capacity for the whole world increased exponentially from 17.4 GW in 2000 to $432.4 \mathrm{GW}$ in 2015, positioning wind power as a significant and crucial energy source in areas as China, USA, and Europe [1]. It is expected a constant increment of wind power capacity in near future. Truthfully, the European Wind Energy Association (EWEA) plan for the next years is to transformate the wind industry in the most competitive energy source, by 2020 onshore and offshore by 2030 . EWEA has stated that "wind power would be capable of contributing up to $20 \%$ of EU electricity by $2020,30 \%$ by 2030 and $50 \%$ by $2050 . "$

An important part of the required future installed wind power will be offshore based, because of the higher wind-energy potential and the lower environmental impacts. Going offshore implies several technology challenges, mainly regarding reliability, efficiency and upscaling. Considering that expensive platforms must support the total weight of the WECS, the size and weight of components are critical, and possible weight reductions become crucial. What is more, it has been demonstrated that high power wind turbines could reduce the cost structure of offshore WECS, this is the reason why upscaling has become the focus of modern wind energy application and research [2].

As is shown in Fig. 1(a), wind turbines manufacturers have been upscaling turbine dimensions. The largest wind turbine by 2014 was the $8 \mathrm{MW}$ Vestas V164, with a diameter of $164 \mathrm{~m}$, currently operating in Denmark. Manufacturers as Sway Turbine AS and Windtec-AMSC have announced $10 \mathrm{MW}$ wind turbines projects. Moreover, GE Energy has ambitious plans to develop 15MW turbines [3]. 

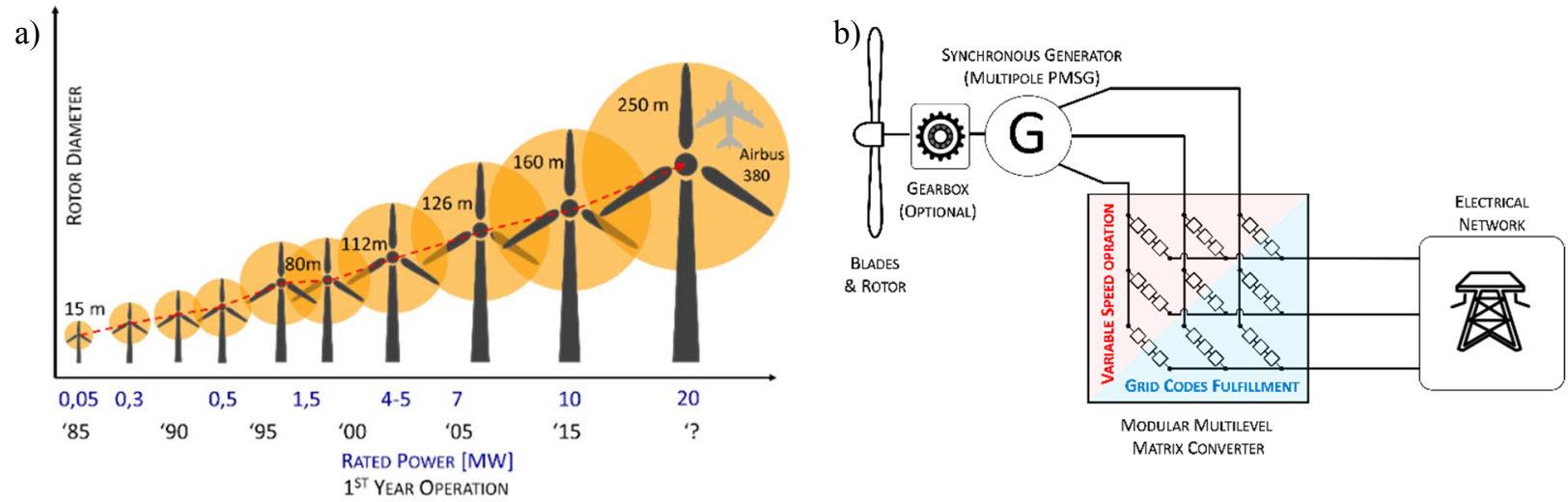

Fig. 1: (a) Wind Turbines Rated Power growth. (b) Proposed topology to drive a High-power Wind Turbines.

However, most of the present WECSs are based on low-voltage two-level voltage source power converters (usually based on $1700 \mathrm{~V}$ IGBT devices for a $690 \mathrm{~V}$ rated output voltage), which is not the technology for high power applications. For example, from $\approx 1660 \mathrm{~A}$ required for a $2 \mathrm{MW}$ system, the current will increase to $\approx 8300 \mathrm{~A}$ for a $10 \mathrm{MW}$ system. This design leads to large currents and consequently large cables are required to connect the converter to the power transformer. Large current transfer also results in large-diameter power cables going down through the tower (for horizontal axis wind turbines), with significant losses and voltage drops.

In this context, this paper presents the novel application of the $\mathrm{M} 3 \mathrm{C}$ to control a high-power WECSs, as is shown in Fig.1 (b). The M3C is a modular AC/AC converter able to reach medium-voltage, or even high-voltage levels, by the series connection of full-bridge modules. This converter has some advantages compared to traditional two-level converters for high-power applications, fundamentally focused on the full modularity and easy extendibility to reach high voltage and high power levels, control flexibility and power quality improvements[4], [5].

A control strategy that allows decoupled control for $\mathrm{M} 3 \mathrm{C}$ in wind energy applications, is analysed and developed in this paper. Similar to the operation of Back-to-Back based WECSs [6], [7] where the presence of a DC-link allows decoupled control of the AC-DC-AC conversion stages, the proposed control strategy provides decoupled operation. The primary function of generator-side control is to extract maximum power at all available wind velocities. On the other hand, the grid-side control is used to regulate the grid-connected operation and grid code fulfilment.

\section{Grid Integration Requirements for WECSs}

In countries with a high penetration of renewable energies, stringent grid codes have been enforced to ensure stable and safe operation of the electrical network. In particular, in countries as Denmark, Germany, UK, dedicated grid codes for grid-connected wind turbines has been developed. Comprehensive reviews of international grid code requirements for connection of wind turbines to generation and transmission systems are presented in [8]

In most of the cases, these grid codes have focused on power quality, power controllability, and Fault Ride Through (FRT) capability. FRT requirements set the behaviour under Low-Voltage RideThrough (LVRT) and High-Voltage Ride Through (HVRT) grid-voltage situations and constitute, likely, the primary concern for wind turbine and power converter manufacturers, due to grid voltage sag-swell conditions are the most prevalent disturbances in the electrical power systems [9]. In fact, according to recent surveys, grid-voltage sags represent $92 \%$ of all disturbances into the grid [9]. Moreover, $88 \%$ of voltage sags are asymmetrical [10]. Formerly, the main concern is the LVRT capability of grid-connected wind turbines.

As shown in Fig. 2, FTR from different national grid codes are slightly different in their requirements for the type, magnitude, and duration of grid-voltage sags[8]. A detailed review and comparison of FRT is presented in [8]. The voltage profiles are given for particular types of faults (symmetrical or asymmetrical), depth of the voltage dips and clearance times. Moreover, some grid codes define different requirements for WECSs connected to the distribution or transmission system. 
Among all the FRT profiles, the German Distribution and Transmission Regulation (E.ON) is likely to set the standard. As is shown in Fig. 2, the German grid code demands to wind turbines to remain connected to the grid even when grid voltage becomes $0 \%$ of its nominal value, which is known as Zero Voltage Ride Through (ZVRT) requirement [3].

Finally, it is important to note that some grid codes demand voltage support. For the duration of the voltage dip the reactive power control must be changed from normal operation -usually unitary power factor- to a maximum voltage support strategy. If it is necessary, the WECS must be able to provide full rated reactive power to help to re-establish the normal grid voltage as soon as possible.

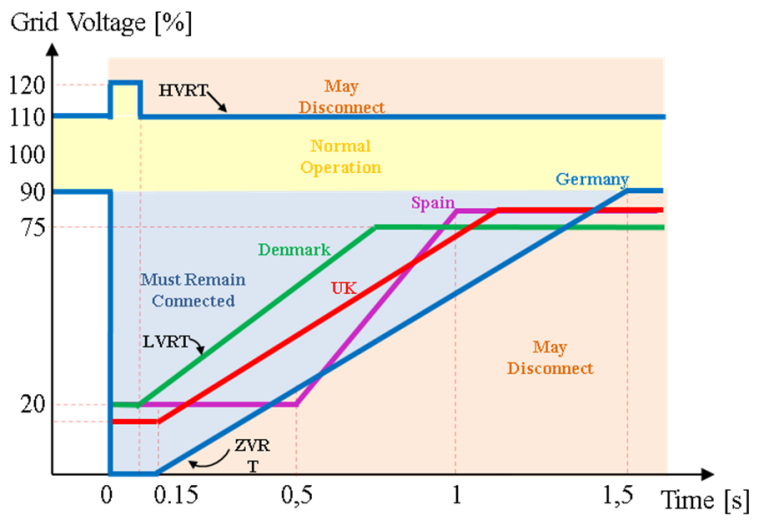

Figure 2: FRT requirements. Voltage profile for simulation of faults in Germany, Denmark, UK and Spain

\section{M3C Overview}

In Fig. 3 the topology of an $\mathrm{M} 3 \mathrm{C}$ is presented, which is composed of 9 branches linking the phases of the input system $(a-b-c)$, to the phases of the output system $(r-s-t)$. As depicted in Fig. 3(b) and Fig. 3(c), these branches are the series connection of $n$ Full H-Bridge based cells and one inductor. The levels and switching frequency of the branch voltage depend on the numbers of cells, which lead to small voltage steps and low harmonic distortion when a high number of cells is considered. Unlike other topologies -as Cascaded H-Bridge-, this topology does not need multiple secondary transformers or multiple DC power sources to operate. DC capacitor voltages are floating and, therefore, can charge-discharge during normal operation of the converter. By this means, the average value of the dc capacitor voltage has to be regulated with low ripple and zero power average value in steady state operation [11]

\section{A. Energy - Capacitor Voltage Relationship}

To analyse the $\mathrm{M} 3 \mathrm{C}$ energy balancing, a single branch as the presented in Fig. 3(b) is used. Neglecting internal losses, the energy stored in a branch with $n$ cells is equivalent to the integral of the power at its terminals. Analogously, the energy of a branch is proportional to the capacitor voltages [5]. Therefore, it is possible to determinate the capacitor voltage using the branch power:

$$
W_{x y}=\int P_{x y} d t \approx \frac{n C}{2} \bar{v}_{c}^{2} \rightarrow P_{x y} \approx n C \bar{v}_{c} \frac{d}{d t}\left(\bar{v}_{c}\right)
$$

a)

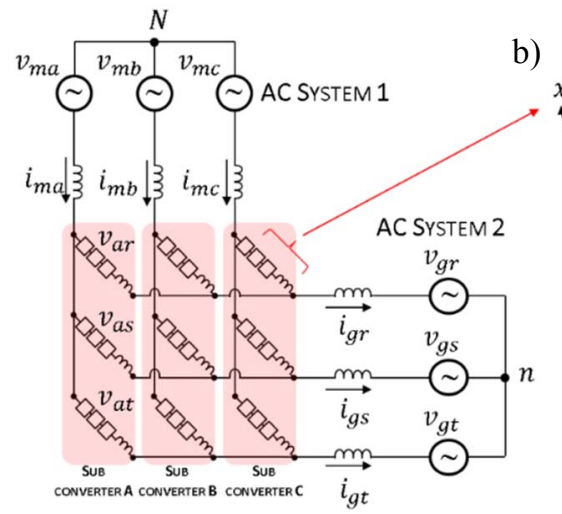

b)

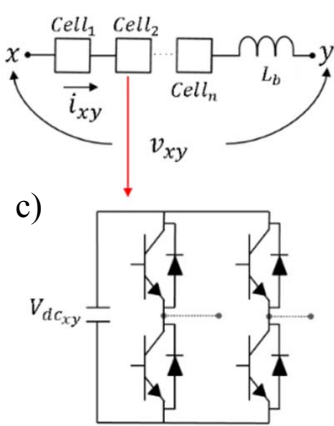

Fig. 3: Modular Multilevel Matrix Converter. (a) Whole converter. (b) M3C Branch composition. (c) M3C Cells. 
where: $x \in\{a-b-c\}, y \in\{r-s-t\}, P_{x y}$ represents the branch power, $\bar{v}_{c}$ is the capacitors average voltage in each cell, $n$ is the number of cells, $C$ represents the capacitance of each capacitor and $W_{x y}$ symbolises the total energy in the $n$ dc capacitors.

\section{$B$. Decoupled Input/Output Modeling for the M3C}

In recent publications, a modelling of the $\mathrm{M} 3 \mathrm{C}$ have been reported (see[11], [12]). In these papers, the basic approach is to use a so-called double- $\alpha \beta 0$ transformation. The main procedure starts applying Kirchhoff's Voltage Law to Fig. 3(a) as follow:

$\left[\begin{array}{lll}v_{m a} & v_{m b} & v_{m c} \\ v_{m a} & v_{m b} & v_{m c} \\ v_{m a} & v_{m b} & v_{m c}\end{array}\right]=L_{b} \frac{d}{d t}\left[\begin{array}{lll}i_{a r} & i_{b r} & i_{c r} \\ i_{a s} & i_{b s} & i_{c s} \\ i_{a t} & i_{b t} & i_{c t}\end{array}\right]+\left[\begin{array}{lll}v_{a r} & v_{b r} & v_{c r} \\ v_{a s} & v_{b s} & v_{c s} \\ v_{a t} & v_{b t} & v_{c t}\end{array}\right]+\left[\begin{array}{lll}v_{g r} & v_{g r} & v_{g r} \\ v_{g s} & v_{g s} & v_{g s} \\ v_{g t} & v_{g t} & v_{g t}\end{array}\right]+v_{N n}\left[\begin{array}{lll}1 & 1 & 1 \\ 1 & 1 & 1 \\ 1 & 1 & 1\end{array}\right]$

The lowercase letter subscripts $m$ represent the machine voltages and currents; whereas the subscript $g$ represent the grid-side variables. The $\alpha \beta 0$ transformation matrix, i.e., $\boldsymbol{C}_{\alpha \beta 0}$ is defined:

$\boldsymbol{C}_{\alpha \beta 0}=\left[\begin{array}{ccc}1 & -1 / 2 & -1 / 2 \\ 0 & \sqrt{3} / 2 & -\sqrt{3} / 2 \\ 1 / 3 & 1 / 3 & 1 / 3\end{array}\right]$

Then, (2) is pre-multiplied by $\boldsymbol{C}_{\alpha \beta 0}$ and post-multiplied by $\boldsymbol{C}_{\alpha \beta 0}^{t}$ yielding:

$\sqrt{3}\left[\begin{array}{ccc}0 & 0 & 0 \\ 0 & 0 & 0 \\ v_{s \alpha} & v_{s \beta} & 0\end{array}\right]=\left[\begin{array}{ccc}v_{\alpha \alpha} & v_{\beta 0} & v_{0 \alpha} \\ v_{\alpha \beta} & v_{\beta \beta} & v_{0 \beta} \\ v_{\alpha 0} & v_{\beta 0} & v_{00}\end{array}\right]+L_{b} \frac{d}{d t}\left[\begin{array}{ccc}i_{\alpha \alpha} & i_{\beta \alpha} & i_{0 \alpha} \\ i_{\alpha \beta} & i_{\beta \beta} & i_{0 \beta} \\ i_{\alpha 0} & i_{\beta 0} & i_{00}\end{array}\right]+\sqrt{3}\left[\begin{array}{ccc}0 & 0 & v_{g \alpha} \\ 0 & 0 & v_{g \beta} \\ 0 & 0 & 0\end{array}\right]+\left[\begin{array}{ccc}0 & 0 & 0 \\ 0 & 0 & 0 \\ 0 & 0 & 3 v_{N n}\end{array}\right]$

According to [12], [11], the transformation presented above represents a decoupled model of the M3C, which enables the full use of the transformed branch currents as degrees of freedom. Using the electric circuit approach proposed in [13], the M3C equivalent circuit is presented in Fig. 4:

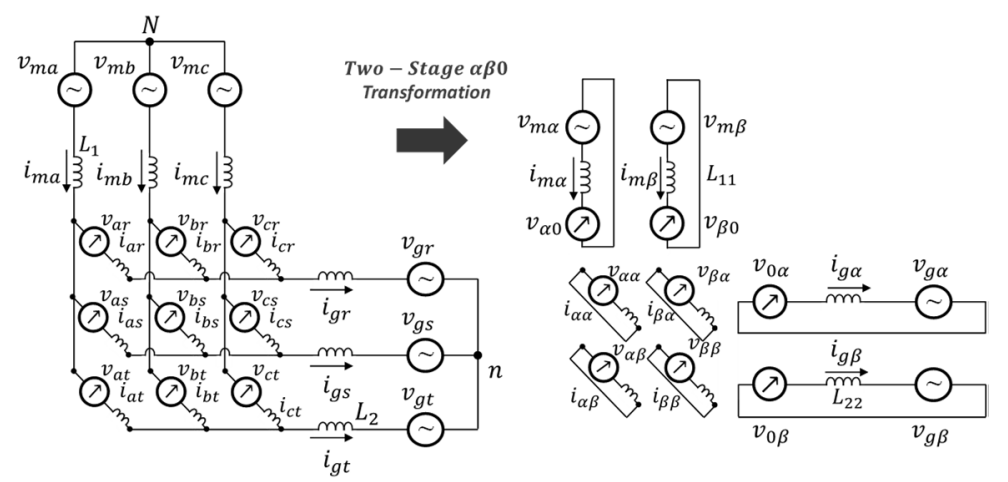

Fig.4: Proposed Modelation of the M3C.

\section{Control Strategy for the M3C based WECSs}

Similar to the operation of Back-to-Back based WECS [7], decoupled input/output control for M3C based WECS is proposed and analysed in this paper. On the one hand, the primary function of the machine-side control system is to extract maximum power at all wind velocities, considering a Permanent Magnet Synchronous Generator (PMSG) based WECSs. On the other hand, the grid-side control is used to regulate the grid-connected operation and provide FRT compliance.

\section{A. Modeling of the Wind Turbine}

The mechanical torque and the power produced by a wind turbine can be expressed as [14], [15]:

$P_{m}=0.5 \pi \rho r_{w t}^{2} C_{p}(\lambda, \beta) v_{w}^{3}$

$T_{m}=0.5 \pi \rho r_{w t}^{3} C_{t}(\lambda, \beta) v_{w}^{2}$

where $v_{w}$ is the wind speed, correspond to the blade pitch angle and $r_{w t}$ is the blades radio. $C_{p}(\lambda, \beta)$ and $C_{t}(\lambda, \beta)$ are the power and torque coefficients, respectively, and $\lambda$ is the tip-speed ratio. Moreover, the power characteristic $C_{p}(\lambda, \beta)$ reported in [15] is used. For each wind velocity, there is a point of maximum power capture from the wind and. If the losses are neglected, it can be demonstrated 
that, in a steady state, the wind turbine operates at an maximum power point tracking (MPPT) when the electrical generator torque is regulated as [15]:

$\tau_{e}=K_{o p t} \omega_{w}^{2} \rightarrow P_{m}=K_{o p t} \omega_{w}^{3}$

where $K_{o p t}$ is a constant that depends on the blade aerodynamic, gear box ratio, and wind turbine parameters and can be calculated as the ratio between the nominal power $P_{\text {nom }}$ the nominal generator rotational speed $\omega_{\text {gen }}$.

\section{B. Modeling and Control of the PMSG-Side M3C Equivalent Circuit}

Permanent Magnet Synchronous Generators $\angle P M S G-i s$ one of the most common gener ators used in wind turbines b16 $\sharp \triangleright$ Considering surface'mounted PMSGs with non’salient ro torc the equations defining the dynamics of the machine are.

$\vec{v}_{m}=R_{m} \vec{\imath}_{m}+\frac{d \vec{\psi}_{s}}{d t}$

$\tau_{e}=\frac{3}{2} p \operatorname{Img}\left\{\vec{\psi}_{s} \vec{\imath}_{m}^{*}\right\}$

$$
\leftarrow 9 \leftarrow
$$

where $\vec{v}_{m}, R_{m}$ and $\vec{l}_{m}$ correspond to the machine voltage, stator resistance and current, respectively. The PMSG pair of poles are represented by $p$ and the stator flux is denoted by $\vec{\psi}_{s}$. As is presented in [15], the PMSG model in the $d q$ reference frame is:

$$
\begin{aligned}
& v_{m d}=R_{m} i_{m d}+L_{s} \frac{d i_{s d}}{d t}-\omega_{r} \psi_{s q} \\
& v_{m q}=R_{m} i_{m q}+L_{s} \frac{d i_{s q}}{d t}+\omega_{r} \psi_{s d}
\end{aligned}
$$

Considering orientation along the stator flux, the current reference for MPPT purposes can be obtained as:

$i_{m q 1}{ }^{*}=\frac{2}{3 \rho \psi_{s d}} \tau_{e}$

The complete control system for the machine-side of the M3C based WECSs is presented in Fig. 5. To operate the wind turbine at the MPPT, the generator electrical torque is calculated as is presented in equation (7), and the $d q$ reference frame control system regulates the quadrature current following the reference obtained in equation (12).

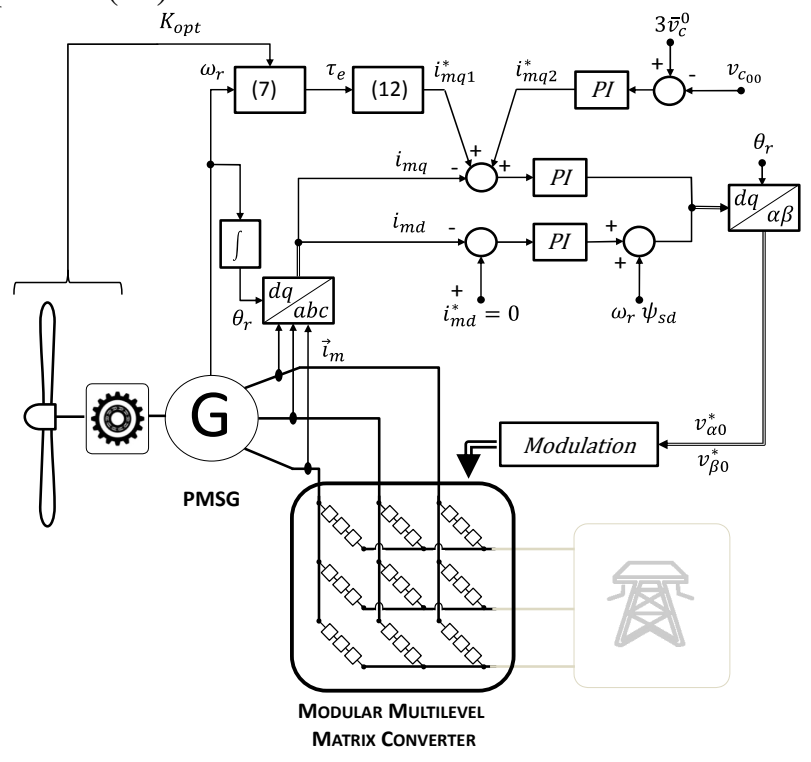

Fig. 5: Machine-Side M3C Control Strategy

\section{Control of the $\mathrm{M3C}$}

From (1), it is possible to express the relationship power/dc-capacitor voltage as: 


$$
\bar{v}_{c}=\frac{1}{n C \bar{v}_{c}^{0}} \int P_{x y}+\bar{v}_{c}^{0}
$$

Where $\bar{v}_{c}^{0}$ represents the capacitor average voltage in one branch -assuming that all capacitors are regulated at the same set point-. Using matrix notation yields:

$$
\left[\begin{array}{lll}
\bar{v}_{c_{a r}} & \bar{v}_{c a s} & \bar{v}_{c_{a t}} \\
\bar{v}_{c_{b r}} & \bar{v}_{c_{b s}} & \bar{v}_{c_{b t}} \\
\bar{v}_{c c r} & \bar{v}_{c_{c s}} & \bar{v}_{c_{c t}}
\end{array}\right]=\frac{1}{n c \bar{v}_{c}^{0}}\left[\begin{array}{lll}
P_{a r} & P_{a s} & P_{a t} \\
P_{b r} & P_{b s} & P_{b t} \\
P_{c r} & P_{c s} & P_{c t}
\end{array}\right] d t+\bar{v}_{c}^{0}\left[\begin{array}{lll}
1 & 1 & 1 \\
1 & 1 & 1 \\
1 & 1 & 1
\end{array}\right]
$$

Applying the two-stage $\alpha \beta 0$ transformation equation (13) yields to:

$\left[\begin{array}{lll}\bar{v}_{c_{\alpha \alpha}} & \bar{v}_{c_{\beta \alpha}} & \bar{v}_{c_{0 \alpha}} \\ \bar{v}_{c_{\alpha \beta}} & \bar{v}_{c_{\beta \beta}} & \bar{v}_{c_{\beta \beta}} \\ \bar{v}_{c_{\alpha 0}} & \bar{v}_{c_{\beta 0}} & \bar{v}_{c_{00}}\end{array}\right]=\frac{1}{3 n c \bar{v}_{d c}^{0}} \int\left[\begin{array}{ccc}P_{\alpha \alpha} & P_{\beta \alpha} & P_{0 \alpha} \\ P_{\alpha \beta} & P_{\beta \beta} & P_{0 \beta} \\ P_{\alpha 0} & P_{\beta 0} & P_{00}\end{array}\right] d t+\left[\begin{array}{ccc}0 & 0 & 0 \\ 0 & 0 & 0 \\ 0 & 0 & 3 \bar{v}_{c}^{0}\end{array}\right]$

Equations (14) and (15) show that the nine power elements are related to nine capacitor voltages. Further, when all the elements left side of (14) are equal to $\bar{v}_{c}^{0}$, capacitor voltages are:

$\left[\begin{array}{ccc}\bar{v}_{c_{\alpha \alpha}} & \bar{v}_{c_{\beta \alpha}} & \bar{v}_{c_{0 \alpha}} \\ \bar{v}_{c_{\alpha \beta}} & \bar{v}_{c_{\beta \beta}} & \bar{v}_{c_{0 \beta}} \\ \bar{v}_{c_{\alpha 0}} & \bar{v}_{c_{\beta 0}} & \bar{v}_{c_{00}}\end{array}\right]=\left[\begin{array}{ccc}0 & 0 & 0 \\ 0 & 0 & 0 \\ 0 & 0 & 3 \bar{v}_{c}^{0}\end{array}\right]$

\section{i. Average Capacitor Voltage Control}

The component $\bar{v}_{c_{00}}$ is related to the average value of all capacitor voltages $\left(3 \bar{v}_{c}^{0}\right)$, and can be controlled using the active power flowing into the converter $P_{00}$. This power component can be expressed as the difference of the input and output converter power:

$P_{00}=P_{\text {in }}-P_{\text {out }}=\frac{3}{2} i_{m q} \rho \psi_{\text {sd }} \omega_{r}-P_{\text {out }}$

From the control point of view, $P_{\text {out }}$ could be considered as a perturbation to the control systems and can be neglected -or feed-forwarded-. Therefore, the current command for regulating the average capacitor voltage using PI controllers in the $d q$ reference frame is:

$i_{m q 2}^{*} \approx \frac{2}{3} \frac{P_{00}}{\rho \psi_{s d} \omega_{r}} \approx \frac{2}{3} \frac{G_{P I}(s) *\left(\bar{v}_{c_{00}}^{*}-3 \bar{v}_{c}^{0}\right)}{\rho \psi_{s d} \omega_{r}}$

Where $G_{P I}(s)$ is the transfer function of the PI controller.

\section{ii. Balancing Capacitor Voltage Control}

The eight remaining components of (15) represent the power between subconverters, or between different branches in the same subconverter. These oscillating power components should be to zero to mitigate the ripple in the capacitor voltages. As is presented in [11], the eight power components can be regulated by imposing the following command to the four circulating currents:

$$
\begin{aligned}
& i_{\alpha \alpha}^{*}=K_{1}\left(-v_{c_{0 \alpha}} \sin \theta_{m}+v_{c_{\alpha 0}} \sin \theta_{g}\right)-K_{2}\left(v_{c_{\alpha \alpha}} \sin \theta_{m}+v_{c_{\beta \alpha}} \cos \theta_{m}\right) \\
& i_{\beta \alpha}^{*}=K_{1}\left(v_{c_{0 \alpha}} \cos \theta_{m}+v_{c_{\beta 0}} \sin \theta_{g}\right)-K_{2}\left(v_{c_{\alpha \alpha}} \cos \theta_{m}-v_{c_{\beta \alpha}} \sin \theta_{m}\right) \\
& i_{\alpha \beta}^{*}=K_{1}\left(-v_{c_{0 \beta}} \sin \theta_{m}-v_{c_{\alpha 0}} \cos \theta_{g}\right)-K_{2}\left(v_{c_{\alpha \beta}} \sin \theta_{m}+v_{c_{\beta \beta}} \cos \theta_{m}\right) \\
& i_{\beta \beta}^{*}=K_{1}\left(v_{c_{0 \beta}} \cos \theta_{m}-v_{c_{\beta 0}} \cos \theta_{g}\right)-K_{2}\left(v_{c_{\alpha \beta}} \cos \theta_{m}-v_{c_{\beta \beta}} \cos \theta_{m}\right)
\end{aligned}
$$

Where $K_{1}$ and $K_{2}$ correspond to proportional gains.

\section{iii. Circulating Current Control}

Due to the topology of the converter, the branch currents, and consequently circulating currents, contain different frequency components (rotating at $\omega_{m}$ and $\omega_{g}$, which represent the input and output frequencies, respectively). Proportional controllers could be well suited for this application, mainly for simplicity and because of the control plant is integrative. The voltage commands to achieve decoupled current control of the four circulating currents should be:

$\left[\begin{array}{cc}v_{\alpha \alpha}^{*} & v_{\beta \alpha}^{*} \\ v_{\alpha \beta}^{*} & v_{\beta \beta}^{*}\end{array}\right]=-K_{3}\left(\left[\begin{array}{cc}i_{\alpha \alpha}^{*} & i_{\beta \alpha}^{*} \\ i_{\alpha \beta}^{*} & i_{\beta \beta}^{*}\end{array}\right]-\left[\begin{array}{ll}i_{\alpha \alpha} & i_{\beta \alpha} \\ i_{\alpha \beta} & i_{\beta \beta}\end{array}\right]\right)$ 
Where $K_{3}$ represent the proportional gain transfer function.

\section{Modeling and Control of the Grid-Side M3C Equivalent Output Circuit.}

When grid-voltages faults appear, unbalanced currents and voltages are produced in the power system. For the implementation of LVRT control systems, usually the measured currents and voltages have to be separated into positive and negative sequence components to eliminate the power oscillations in the active -or reactive- power injected into the grid. As is reported in [17], the currents, the powers and the voltages are related by:

$\left[\begin{array}{l}i i_{g \alpha}^{p} \\ i_{g \beta}^{p} \\ i_{g \alpha}^{n} \\ i_{g \beta}^{n}\end{array}\right]=\left[\begin{array}{cccc}v_{g \alpha}^{p} & v_{g \beta}^{p} & v_{g \alpha}^{n} & v_{g \beta}^{n} \\ v_{g \beta}^{p} & -v_{g \alpha}^{p} & v_{g \beta}^{n} & -v_{g \alpha}^{n} \\ v_{g \beta}^{n} & -v_{g \alpha}^{n} & -v_{g \beta}^{p} & v_{g \alpha}^{p} \\ v_{g \alpha}^{n} & v_{g \beta}^{n} & v_{g \alpha}^{p} & v_{g \beta}^{p}\end{array}\right]^{-1}\left[\begin{array}{l}P_{g_{0}} \\ Q_{g_{0}} \\ P_{f_{s 2}} \\ P_{f_{c 2}}\end{array}\right]$

Where the superscripts $p$, and $n$ are utilised to symbolise the positive and negative-sequence components, respectively. To achieve sequence separation, Delayed-signal-cancellation (DSC) is probably the best-suited method [6], but has an intrinsic delay of $4.166 \mathrm{~ms}$ (for $\omega_{s}=60 \mathrm{~Hz}$ ) before achieving the separation of the sequence components. To reduce the inherent delay present in traditional DSC, the fast convergence DSC proposed in [18] is utilised in this work to calculate (24). Resonant Controllers (RC) are applied to regulate the M3C Equivalent Output Circuit, mainly because of RC can be used to adjust positive and negative sequence current at the same time, and only two controllers are needed instead of four for $d q$ control systems [7], [17]. The complete control structure for the M3C Equivalent Output Circuit is presented in Fig. 6:

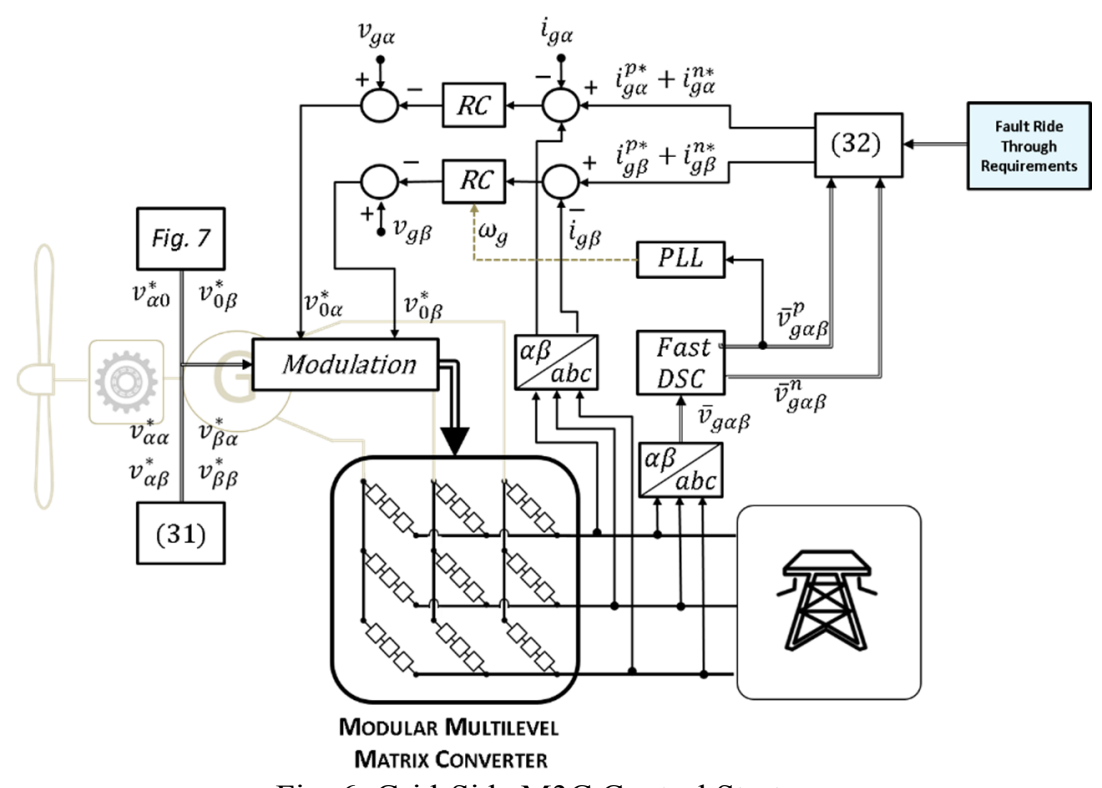

Fig. 6: Grid-Side M3C Control Strategy

\section{E. Cell balancing algorithm and Modulation Scheme}

The voltage references obtained in control loops presented abode, i.e. $v_{\alpha \alpha}^{*}, v_{\beta \alpha}^{*}, v_{\alpha \beta}^{*}, v_{\beta \beta}^{*}, v_{\alpha 0}^{*}, v_{\beta 0}^{*}, v_{0 \alpha}^{*}, v_{0 \beta}^{*}$, are transformed to the natural reference frame using the two-stage inverse $\alpha \beta 0$-Transformation. An additional control loop is utilised to ensure equal de capacitor voltages within a branch. This control scheme is presented in Fig. 7 and was firstly proposed for STATCOM applications [19].

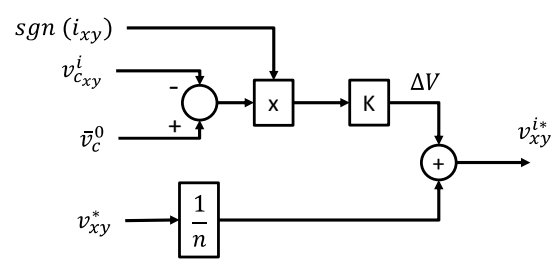

Fig. 7: Individual capacitor voltages balancing control. 
The voltage reference " $v_{x y}^{*}$ " is distributed among the number of cells in the $x-y$ branch. The capacitor voltage for the cell number " $i$ ", with $i \in(1, n)$, is compared with the desired value " $\bar{v}_{c}^{o}$ ". Then, the error is multiplied for the sing of the branch current, resulting in releasing/absorbing active power to each bridge cell. This power results in the addition/subtraction of a $\Delta V$ to the cell voltage reference [11], keeping then all cells controlled to the same set point voltage within a branch.

\section{Results}

A simulation model for five cells per branch M3C has been implemented using PLECS software. The system has been tested for variable speed operation, and grid voltage dips. The general parameters used in the simulation are depicted in Table I and Table II:

Table I: Wind Turbine Parameters

\begin{tabular}{c|c}
\hline Average wind speed & $9.5 \mathrm{~ms}$ \\
\hline Generator Type & PMSG \\
\hline Blades Radio & $89 \mathrm{~m}$ \\
\hline Generatior Inertia & $750 \mathrm{~m} / \mathrm{kg} 2$ \\
\hline Ls & $0.12 \mathrm{mH}$ \\
\hline Rs & $0.15 \mathrm{Ohm}$ \\
\hline Nominal Speed & $375 \mathrm{rpm}$ \\
\hline
\end{tabular}

Table II: Converter Parameters

\begin{tabular}{c|c}
\hline Nominal Power & $10 \mathrm{MW}$ \\
\hline Cells per branch & 5 \\
\hline Input Voltage/Frequency & $5.4 \mathrm{kV} / 10-40 \mathrm{~Hz}$ \\
\hline Branch Inductor & $2.5 \mathrm{mH}$ \\
\hline Capacitance in each cell & $2.8 \mathrm{mF}$ \\
\hline DC-Capacitor Voltage & $2.4 \mathrm{kV}$ \\
\hline Output Voltage/Frequency & $5.4 \mathrm{kV} / 60 \mathrm{~Hz}$ \\
\hline Switching frequency & $2.5 \mathrm{kHz}$ \\
\hline
\end{tabular}

\section{A. Variable Speed Operation:}

A 10MW wind turbine is emulated, using the methodology described in the previous section, to test the performance of the proposed M3C based WECSs A wind speed profile, from Rutherford Appleton Laboratories, is applied during $30 \mathrm{~s}$. As can be observed in Fig. 8(a), the wind speed profile generates a variable PMSG rotational speed, which implies variable frequency and emulates the behavior of a variable speed wind turbine at the input of the M3C (see Fig. 8(b)). In this scenario, the M3C control system for the input side is able to track the maximum power point for each wind velocity, achieving MPPT operation through the regulation of the quadrature current.

The capacitor voltage control of the $\mathrm{M} 3 \mathrm{C}$ is also verified in this test. The floating capacitor voltages keep their references throughout the test, independently of the input frequency, as is depicted in Fig. 8(d). An Amplified view of the capacitor voltages is presented in Fig. 8(e), where is observed that the capacitor ripple is less than $5 \%$. To ensure the correct operation of the $\mathrm{M} 3 \mathrm{C}$, the branch capacitor voltages must be regulated to a setpoint $(12 \mathrm{kV})$ greater than the sum of the input voltage peak $(5.4 \mathrm{kV})$ plus the output voltage peak $(5.4 \mathrm{kV})$. During the test, the output power is regulated to operate with unitary power factor, dispatching into the grid all the power produced by the wind turbine, Fig. 8(f).

\section{B. LVRT Operation:}

The application of the M3C under unbalanced grid-voltage sags is presented in Fig. 9. As observed, before the grid-fault, the proposed control strategy allows proper operation of the converter keeping regulation of the capacitor voltages, input currents and voltages and output currents and voltages. In $\mathrm{t}=0.2 \mathrm{~s}$, a two phase to ground ansynmetricl grid fault is introduced. The control of the M3C is realised to fulfill the German grid code, which is likely setting the standard to ZVRT and LVRT profiles[9]. When the fault is applied, phases ' $s$ ' and ' $t$ ' reduce their voltages to $0 \mathrm{~V}$ for $150 \mathrm{~ms}$. Afterwards, a recovery profile is imposed during $1.5 \mathrm{~s}$ until to reach the nominal value in both failure phases (Fig.9 (a) and Fig. 9(b)). At the fault beginning, the PMSG-Side Control System stops the active power generation by reducing the quadrature current reference to zero (Fig. 9(c)). The Grid-Side Control System regulates the grid currents using reference currents calculated from (24), which generates unbalanced current injected into the grid (see Fig. 9(b)) to mitigate active power double-frequency oscillations, and providing reactive power injection. As shown in Fig. 9(d), there are not doublefrequency oscillations in active power, but reactive power presents double frequency oscillations that cannot be controlled because there are not enough degrees of freedom [8].

The capacitor voltages are presented in Fig. 9(e) and Fig. 9(f). As observed, proper energy balancing is achieved when grid the voltage fault occurs. When the fault is applied, a slight voltage oscillation increase is observed. Nonetheless, it can be observed that the dc capacitor voltage is not affected 
thought the grid fault and through the whole test the ripple does not exceed the 5\% of the nominal value.
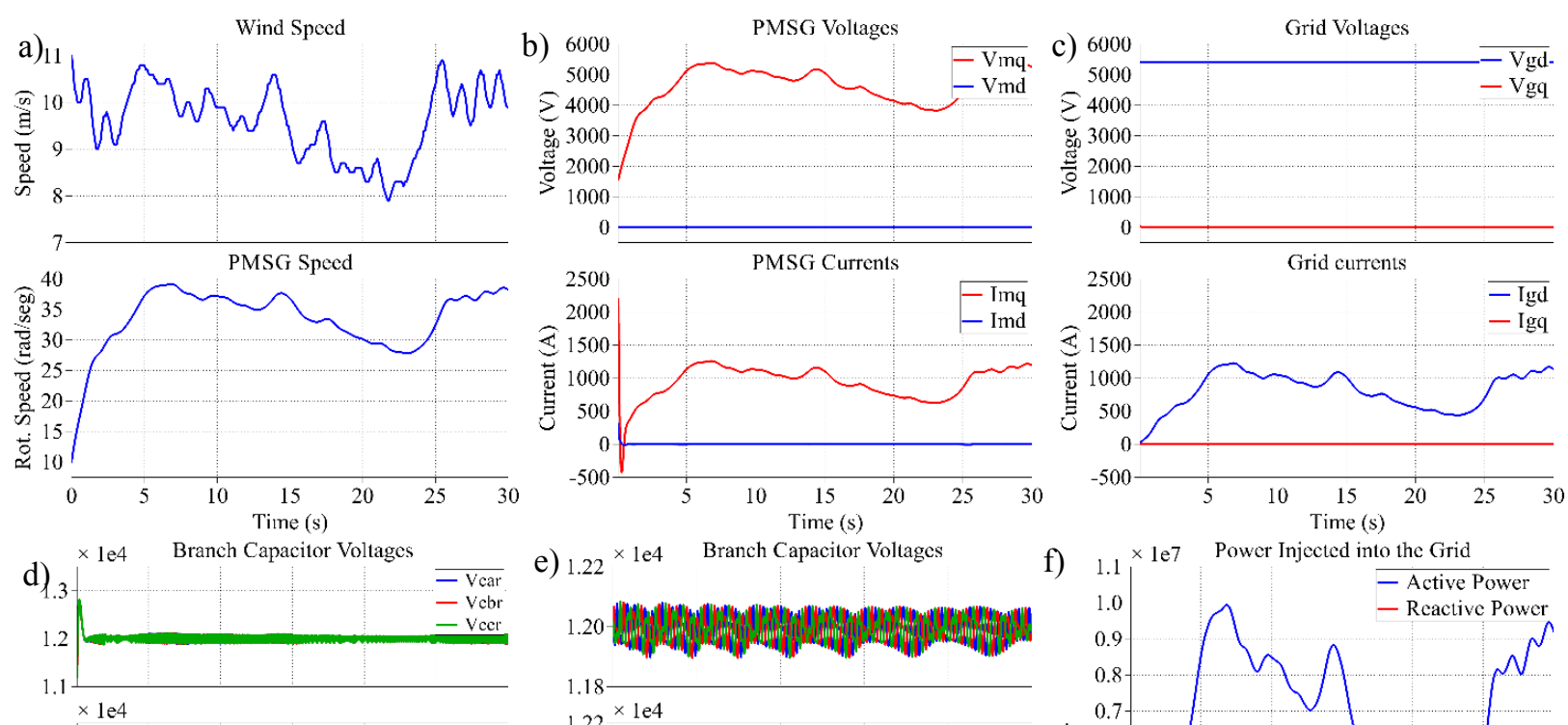

e) $1.22 \times 1 \mathrm{e} 4 \quad$ Branch Capacitor Voltages

f)
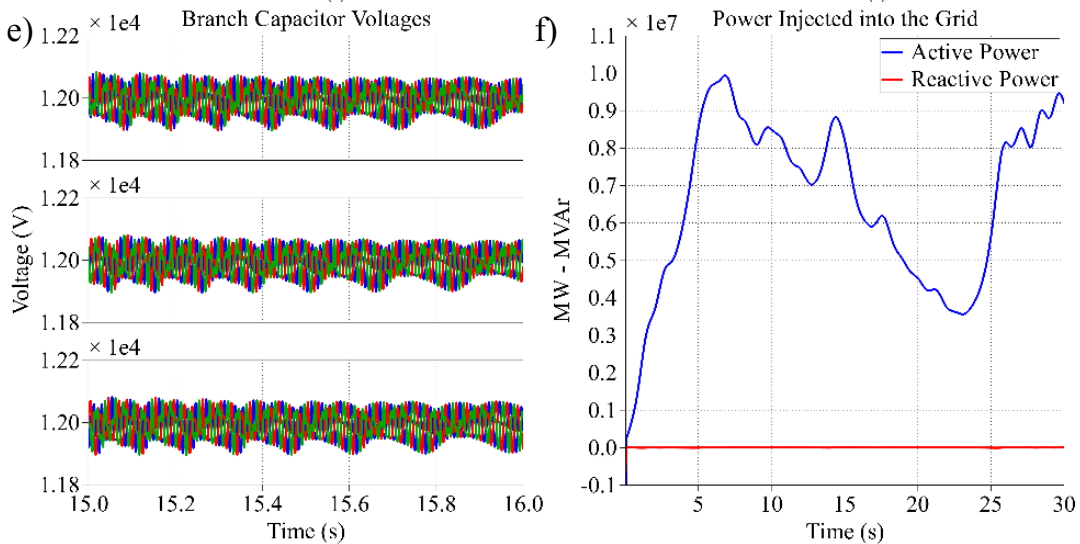

Fig:8: (a) Wind Speed and PMSG Rotational Speed. (b) PMSG Voltages and Currents in dq reference frame. (c) Grid Voltages and Current in equivalent dq reference frame. (d) Branch Capacitor Average Voltages. (e) Amplified view of (d). (e) Power Injected to the grid.
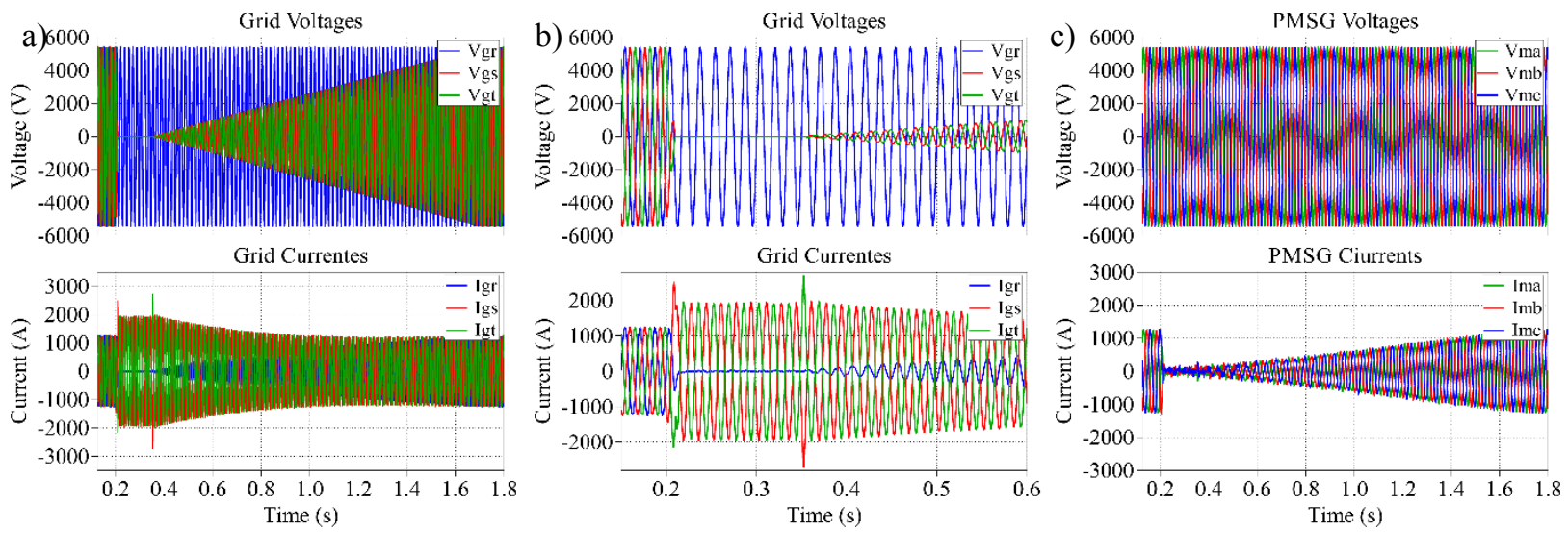

$\times 1 \mathrm{e} 7 \quad$ Power Injected into the Grid
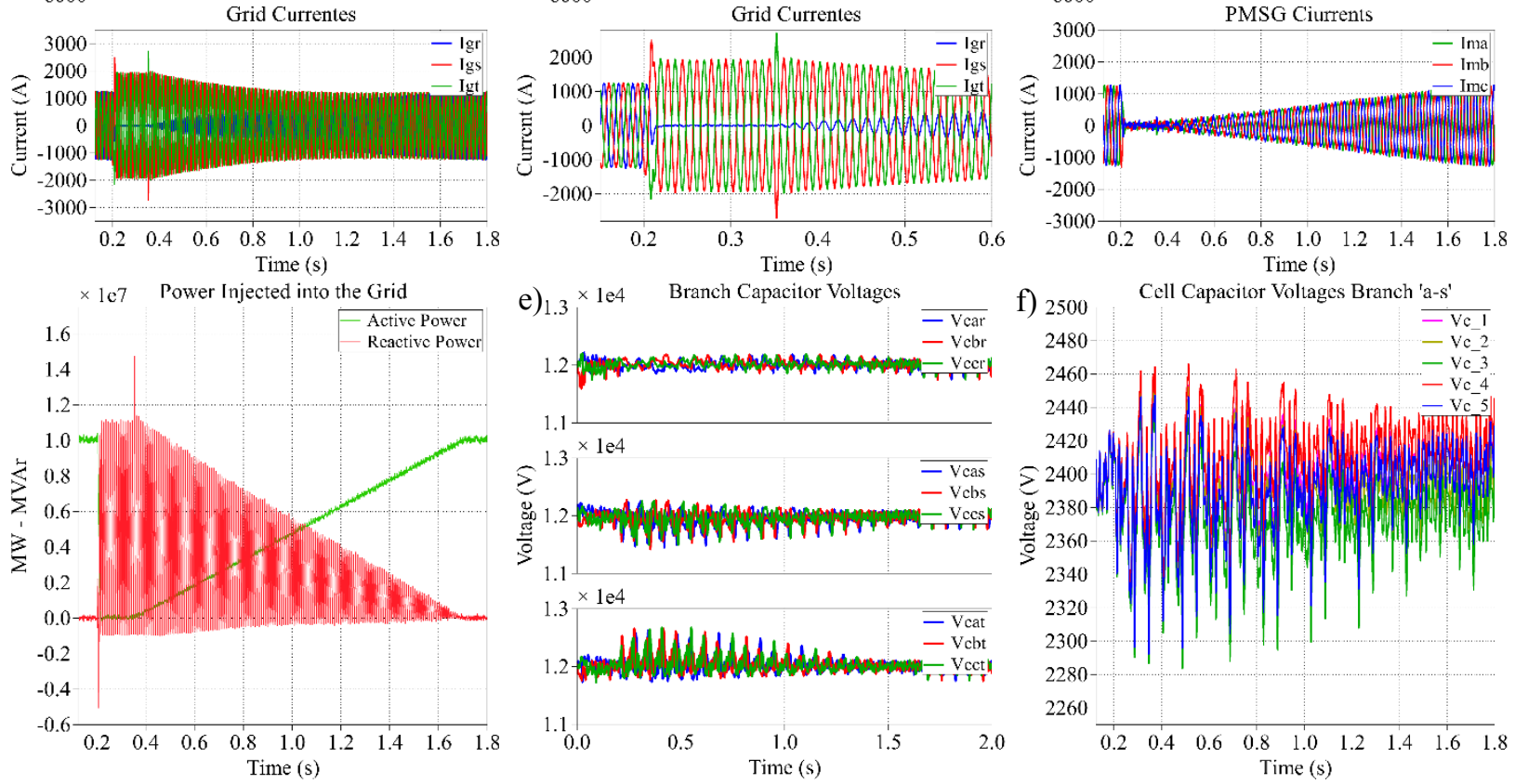
Fig 9: (a) Output voltages and currents fed into the grid. (b) Amplified view of (a). (c) Input voltages and currents. (d) Active and Reactive Power injected into the grid. (e) Average Branch Capacitor Voltages for SubConver A, B and C, respectively. (f) Cell Capacitor Voltages for branch "a-s".

\section{Conclusions}

This paper has described the application of an M3C based high-power WECS. Due to the topologies characteristics, this converter is well suited for high power applications. Extensive discussion on modelling and control of the $\mathrm{M} 3 \mathrm{C}$ has been presented, proposing a decoupled control strategy for the application of the Modular Multilevel Matrix Converter in high-power WECS. Three equivalent circuits for decoupled control of the input, converter and output, are obtained by using the two-stage $\alpha \beta 0$ transformation.

The proposed control strategy has been validated through simulations obtained from a $10 \mathrm{MW}$ M3C based WECS. Using the PMSG-based Equivalent Circuit Control, it has been validated that the proposed topology correctly performs MPPT operation for variable speed applications. Moreover, controlling the Grid-Side M3C Equivalent Output Circuit, it is possible to fulfill LVRT and ZVRT requirements. Accordingly, the strategy is able to keep the system operating through grid-voltage dips, even when grid-voltage becomes zero, and inject reactive power to support to the grid voltage.

\section{References}

[1] “Global Wind Statistics 2015." [Online]. Available: http://www.gwec.net/wp-content/uploads/vip/GWECPRstats-2015_LR.pdf. [Accessed: 19-Feb-2016].

[2] "Upwind: Design limits and solutions for very large wind turbines." [Online]. Available: http://www.ewea.org/publications/reports/upwind/. [Accessed: 20-Jan-2015].

[3] V. Yaramasu, B. Wu, P. C. Sen, S. Kouro, and M. Narimani, "High-Power Wind Energy Conversion Systems: State-of-the-Art and Emerging Technologies," Proc. IEEE, vol. 103, no. 5, 2015.

[4] A. Mora, M. Espinoza, M. Diaz, and R. Cardenas, "Model Predictive Control of Modular Multilevel Matrix Converter," in 2015 IEEE 24th International Symposium on Industrial Electronics (ISIE), 2015, pp. 10741079 .

[5] A. Korn, M. Winkelnkemper, P. Steimer, and J. W. Kolar, "Direct modular multi-level converter for gearless low-speed drives." pp. 1-7, 2011.

[6] S. Alepuz, S. Busquets-Monge, J. Bordonau, J. A. Martinez-Velasco, C. A. Silva, J. Pontt, and J. Rodriguez, "Control Strategies Based on Symmetrical Components for Grid-Connected Converters Under Voltage Dips," IEEE Trans. Ind. Electron., vol. 56, no. 6, pp. 2162-2173, Jun. 2009.

[7] M. Diaz and R. Cardenas, "Analysis of synchronous and stationary reference frame control strategies to fulfill LVRT requirements in Wind Energy Conversion Systems," in 2014 Ninth International Conference on Ecological Vehicles and Renewable Energies (EVER), 2014, pp. 1-8.

[8] N. C. F. Iov, A. Hansen, P. Sørensen, "Mapping of grid faults and grid codes," Risø-R-1617(EN) $41 p$.

[9] O. S. Senturk and A. M. Hava, "A simple sag generator using SSRs," in 2010 IEEE Energy Conversion Congress and Exposition, 2010, pp. 4049-4056.

[10] R. Cárdenas, R. Peña, S. Alepuz, and G. Asher, "Overview of Control Systems for the Operation of DFIGs in Wind Energy Applications," IEEE Trans. Ind. Electron., vol. 60, no. 7, pp. 2776-2798, 2013.

[11] W. Kawamura, M. Hagiwara, and H. Akagi, "Control and Experiment of a Modular Multilevel Cascade Converter Based on Triple-Star Bridge Cells," IEEE Trans. Ind. Appl., vol. 50, no. 5, pp. 3536-3548, Sep. 2014.

[12] F. Kammerer, J. Kolb, and M. Braun, "Fully decoupled current control and energy balancing of the Modular Multilevel Matrix Converter," in 2012 15th International Power Electronics and Motion Control Conference (EPE/PEMC), 2012, pp. LS2a.3-1-LS2a.3-8.

[13] M. Diaz, R. Cardenas, M. Espinoza, A. Mora, and F. Rojas, "A novel LVRT control strategy for Modular Multilevel Matrix Converter based high-power Wind Energy Conversion Systems," in 2015 Tenth International Conference on Ecological Vehicles and Renewable Energies (EVER), 2015, pp. 1-11.

[14] E. Muljadi and C. P. Butterfield, "Pitch-controlled variable-speed wind turbine generation," IEEE Trans. Ind. Appl., vol. 37, no. 1, pp. 240-246, 2001.

[15] R. PeÑa, R. CÁrdenas, J. Proboste, J. Clare, and G. Asher, "Wind-Diesel Generation Using Doubly Fed Induction Machines," IEEE Trans. Energy Convers., vol. 23, no. 1, pp. 202-214, Mar. 2008.

[16] M. Liserre, R. Cardenas, M. Molinas, and J. Rodriguez, "Overview of Multi-MW Wind Turbines and Wind Parks," IEEE Trans. Ind. Electron., vol. 58, no. 4, pp. 1081-1095, Apr. 2011.

[17] M. Diaz, R. Cardenas, P. Wheeler, J. Clare, and F. Rojas, "Resonant Control System for Low-Voltage RideThrough in Wind Energy Conversion Systems," IET Power Electron., pp. 1-16, Feb. 2016.

[18] R. Cardenas, M. Díaz, F. Rojas, and J. Clare, "Fast Delayed Signal Cancellation Method for Component 
Sequences Separation," IEEE Power Eng. Lett., no. Submitted.

[19] H. Akagi, S. Inoue, and T. Yoshii, "Control and Performance of a Transformerless Cascade PWM STATCOM With Star Configuration,” IEEE Trans. Ind. Appl., vol. 43, no. 4, pp. 1041-1049, 2007. 